\title{
A COMPARATIVE STUDY IN DACRYOCYSTORHINOSTOMY WITH VERSUS WITHOUT SILICON TUBE INTUBATION IN NASOLACRIMAL DUCT OBSTRUCTION IN ADULTS
}

\author{
Salih, M. ${ }^{1{ }^{(*)}}$, Abd El-Rahman, Y. ${ }^{2}$, Abd El-badie, M. ${ }^{1} \&$ Ismael, A. ${ }^{3}$ \\ ${ }^{1}$ Ophthalmology dept., Faculty of Medicine, Al-Azhar Univ., Assiut, Egypt \\ ${ }^{2}$ Otorhinolaryngology dept., Faculty of Medicine, Al-Azhar Univ., Assiut, Egypt \\ ${ }^{3}$ Ophthalmology dept., Faculty of Medicine, Sohag Univ., Sohag, Egypt \\ *E-mail: justelaraby1@yahoo.com
}

\begin{abstract}
Background: Dacryocystorhinostomy (DCR) has been touted as the standard procedure for treatment of acquired nasolacrimal duct obstruction; it can be performed through a cutaneous incision referred to as external DCR, or via a transnasal approach. Intubation with silicone tubes has been widely used in lacrimal duct surgery. Objective: Toevaluate the role of silicon tube intubation in the clinical outcomes of external and endonasal dacryocystorhinostomy in nasolacrimal duct obstruction in adults. Patients and Methods: This is a prospective, randomized; comparative study included 80 cases of 74 patients who were diagnosed with postsaccal obstruction of the lacrimal pathway. The studied sample was randomly grouped into two main groups ( $n=40)$, group (I) undergoneexternal dacryocystorhinostomy (EX_DCR) and group (I) undergoneendonasal dacryocystorhinostomy (EN_DCR), then each group was subdivided into two subgroups $(n=20)$ according to with or without silicon tube intubation. From all patients, full history was taken and they received a complete ophthalmologic examination, ENT and systemic assessment. After undergoing the surgical procedure, patients were followed up at1stpostoperative day, 1 week, 1, 3 \& 6 months, complications and outcome were assessed. Results: The overall success rate in external DCR was $82.5 \%$ (33 cases), however, the overall success rate in endonasal DCR was $77.5 \%$ (31 cases) with no significant difference between groups. The success rate was $85 \%$ for external DCR with intubation, $80 \%$ for external DCR without intubation, $80 \%$ forendonasal DCR with intubation and was $75 \%$ for endonasal DCR without intubation, with non significant differences among these subgroups $(P=0.89)$. The results showed that $D C R$ s without intubation recorded significantly lower operative time compared to with indubation DCRs. Conclusion: The results of endoscopic and external DCR with silicone intubation were comparable to these result without intubation with non significant differences. Using of silicone tube has no significant beneficial effect in the surgical success of primary DCR, while, it is associated with increasing cost, operative time and complication rate, there is no need for its routine use. Further studies with larger sample size are warranted.
\end{abstract}

Keywords: Dacrtocystorinostomy, Silicon tube, Nesolacrimal duct obstruction

\section{Introduction}

Dacryocystorhinostomy (DCR) is a surgical procedure to create drainage between the lacrimal sac and nasal cavity, it is the standard procedure for acquired 
nasolacrimal duct obstruction (NLDO) and it can be performed through a cutaneous incision referred to as external DCR, or via a transnasal approach. In both approaches, the lacrimal sac mucosa is connected to the nasal mucosa above the level of the mechanical obstruction at the nasolacrimal duct [1]. Silicone intubation has been routinely used in DCR surgery for primary acquired nasolacrimal duct obstruction (PANDO) [2]. The primary rationale for the use of routine intubation in DCR for NLDO is that it maintains patency of the common canalicular opening into the sac preventing closure due to possible trauma or inflammation [3]. Moreover it prevents the osteal closure as the tubes maintain the ostium from the sac to the nose and acting

\section{Patients and Methods}

This was a prospective, randomized, interventional, comparative study included a total of 80 cases of 74 patients who were diagnosed with postsaccal obstruction of the lacrimal pathway that was conducted in the department of ophthalmology and otorhinolaryngiology, Al-Azher University. hospital, Assuit between January 2016 and June 2017. Inclusion criteria were adult patients with symptomatic epiphora, chronic dacryocystitis or lacrimal sac mucocele with age above 18 years. Patients with canalicular and punctal obstruction, lacrimal fistula, noticeable lower lid laxity, previous lacrimal surgery, ectropion or entropion and unfit patients for general anesthesia were excluded from the study. The studied sample was randomly grouped into two main groups of equal size then each group was subdivided into two subgroups as follow:

* Group (I): Included 40 cases who did external dacryocystorhinostomy (EX_ DCR) and divided in to two subgroups:

- group (Ia) which included 20 cases who undergone external dacryocystorhinostomy with silicon tube intubation. - group (Ib) which included 20 cases as a guard against fibrosis. In uncertain or complicated DCR surgeries, the technique of intubation could ensure a successful outcome. With the passage of time, this practice became accepted as a fact [4]. Although the intubation is a routine on the other hand the use of stenting in dacryocystorhinostomy for PANDO in the absence of canalicular disease is controversial and there is no evidence in the literature to suggest improved anatomical patency in DCR for anatomical obstructions at either the canalicular or the ostial level [5]. In our study we evaluated the role of silicon tube intubation in the clinical outcomes of external and endonasal dacryocystorhinostomy in nasolacrimal duct obstruction in adults.

who done external dacryocystorhinostomy without silicon tube.

* Group (II): Included 40 cases who did endonasal dacryocystorhinostomy (EN_DCR) and divided in to two subgroups:

- group (IIa) which included 20 cases who were doneendonasal dacryocystorhinostomy with silicon tube intubation. - group (IIb) which included 20 cases who undergoneendonasal dacryocystorhinostomy without intubation. All surgeries were performed under general anaesthesia after taking informed consent from all patients. All patients received a complete ocular, ENT and systemic assessment for confirmation of postsacal lacrimal obstruction in the form of complete history tacking, complete ophthalmic examination which was including visual acuity, lid examination, corneal and conjunctival examination, regurgitation test, lacrimal sac syringing and diagnostic lacrimal probing. A nasal examination was also done by an otorhinolaryngologist for all patients to assess the feasibility of the surgery and rule out associated rhino-sinus pathology and abnormalities. Systemic 
examination was also done including medical fittness and systemic investigation including (Random blood glucose, CBC,

\section{Surgical Techniques}

\subsection{External dacryocystorhinostomy}

All procedures were performed under general anesthesia with hypotensive technique. A nasal tamponade was applied to induce vasoconstriction using a gauge soaked in adrenaline, diluted $(1: 100,000)$ or $(1: 200,000)$, for $10 \mathrm{~min}$. A curvilinear incision was performed of about 10-12 $\mathrm{mm}$ in length, 3-4 $\mathrm{mm}$ from the medial canthus along the anterior lacrimal crest. Blunt dissection was carried on to reach the periosteum, the medial canthal tendon was dissected, then the periosteum was separated and reflected laterally from the bone by periosteal elevator to expose the lacrimal fossa. Once the lacrimal fossa was exposed, bone punching was started to create a large size rhinostomy by kerrison bone punch. Then to create the lacrimal sac flaps, a Bowman's probe was passed through the lower punctum and bent in such

\subsection{Endoscopic endonasal dacryocystorhinostomy}

All procedures were performed under general anaesthetic, using $0^{\circ}$ rigid endoscopes Neurosurgical patties soaked with 1:1000 adrenaline were placed in the nose for 5 minutes to achieve local vasoconstriction. Submucosal injection of (2\% lignocaine, 1:80.000 adrenaline) anterior to the axilla of the middle turbinate was performed to produce hydro dissection and vasoconstriction of the mucosal flap. The mucosal incision was made 5 to 10 $\mathrm{mm}$ anterior to the attachment of the middle turbinate with a sickle knife. A posteriorly based mucosal flap was elevated and the bone corresponding to nasal projection of the lacrimal sac was removed with a drill till exposure of the medial wall of the sac. Once the sac was coagulation profile, liver and kidney function). a way to tent the sac as posterior as possible to create a large anterior and small posterior flap. Using the probe as guide, an "H"-shaped incision was made across the sac from the fundus to the nasolacrimal duct. Flaps are raised and the posterior small lacrimal flap was cut. Then incision was made in the nasal mucosa along the bony ostium except anteriorly to have a hinged flap. The large anterior nasal flap was raised and the posterior small residual flap is cut. A silicone stent was inserted and tied in only 20 cases. The anterior nasal mucosal flap was sutured to the anterior flap of the lacrimal sac. Subsequent, the orbicularis was sutured with 6-0 Vicryl followed by the skin with 6-0 silk a running 6-0 polypropylene skin suture is applied.

exposed, a posterior vertical incision of the wall of the sac was performed with a Beaver angle knife. This creates anteriorly large, and posteriorly, small based flaps, thereby marsupialising the sac and covering the exposed bone as much as possible. A silicone stent was inserted and tied in only 20 cases. Patients were advised (Amoxicillin-Clavulanic Acid) $1000 \mathrm{mg}$ twice daily and Diclofinac sodium $50 \mathrm{mg}$ twice daily for 7 days, (TobramycinDexamethasone) eye drops 3 times daily for one week and Nasal decongestants and saline douching of the nasal cavity for 10 days. Skin sutures were removed after 7 days in external DCR cases and the silicon tube was removed at 6 months after surgery in intubated patients.

\subsection{Follow-up and post operative evaluation}

The follow-up period for patients was done at first postoperative day, 1 week, 1 month, 3 months and 6 months. The post operative evaluation were be for symptoms of epiphora, any episode of postoperative dacryocystitis, syringing of lacrimal drainage system, also any intraoperative or postoperative complications were be recorded. A successful outcome was defined as resolution of the patient 
symptoms like epiphora and discharge and/or recurring infection at 6 months follow-up and a patent lacrimal system on irrigation. Failure was accepted as symptomatic epiphora and/or infection

\subsection{Statistical analysis}

Data was statistically analyzed using SPSS v.20 (Statistical Package for Social Science). Categorical variables were described by number and percent (No., \%), however, continuous variables were described by mean \pm standard deviation (Mean $\pm \mathrm{SD}$ ). Chi-square test was used to compare between categorical variables, however, the comparison between continuous variables was

\section{Results}

In the present study, the age of patients ranged between 22 and 58 year with age predominance was in group (31-40) which were 22 cases $(27.5 \%)$ and in group (41-50) which were 32 cases $40 \%$. The mean age was 44 years. Females were predominant in the study than males with male to female ratio of (31.1/68.9\%), fig. (1). Chronic dacryocystitis with mucopurulent discharge was found to be the most common cause of NLDO and it presented about $(57.5 \%)$ of the studied cases and 26 cases $(32.5 \%)$ with mucocele and 30 cases $(37.5 \%)$ with epiphora, fig. (2). The overall success rate in external DCR was $82.5 \%$ (33 cases); however, the overall success rate in endonasal DCR was $77.5 \%$ (31 cases) with no significant difference between groups, tab. (1). Generally, there was no significant difference among subgroups regarding success rate $(\mathrm{P}=0.89)$, tab. (2). The success rate of external DCR with intubation (group Ia) was $85 \%$ (17 cases from 20) and for external DCR without intubation (group Ib) was $80 \%$ (16 cases from 20). The results showed that there was no significant difference between these subgroups regarding success rate with $(\mathrm{P}=0.67)$. Also, the success rate of endonasal DCR with intubation (group IIa) was $80 \%$ (16 cases from 20) and for endonasal at long-term follow-up, as well as documented obstruction by simple irrigation of upper and lower canalicular systems.

performed by t-test, Mann-Whitney U or one way ANOVA tests. Duncan test was used to test the significance among studied subgroups regarding operative time. Probability value ( $\mathrm{P}$. value) of $(<0.05)$ was considered as a significant difference and if $P$. value was $(<0.01)$, the difference is considered as highly significant.

DCR without intubation (group IIb) was $75 \%$ (15 cases from 20). The results showed that there was no significant difference between these subgroups regarding success rate $(P=0.71)$, tab. (2). As regard complication of intubation we found 5 cases with punctual cheesewiring 2 cases in group Ia and 3 cases in group IIa. Conjunctival irritation was present in 8 cases 5 in group Ia and 3 in group IIa. Regarding stent prolapse it occurred in 5 cases 3 in group Ia and 2 in group IIa, fig. (3). Regarding mean operative time, the higher operative time mean was recorded in group Ia (61.8 min.), follow it with a significant difference group Ib (53.2 min.), however the lower mean operative time was recorded in group IIb (41.2 min.). Overall, DCRs without intubation recorded significantly lower mean operative time compared to with indubation DCRs, tab. (3). Figure (4-a) showing a case of preoperative mucoid lacrimal discharge, while fig. (4-b) showing the same case 1 week postoperative after successful EX.DCR without intubation. Figure (5) showing a case of successful endonasal DCR without intubation 3 months postoperative. Figure (6) showing examples of tube complication, fig. (6-a) a case of punctal cheese wiring, while fig. (6-b) showing a case of stent prolapse. 


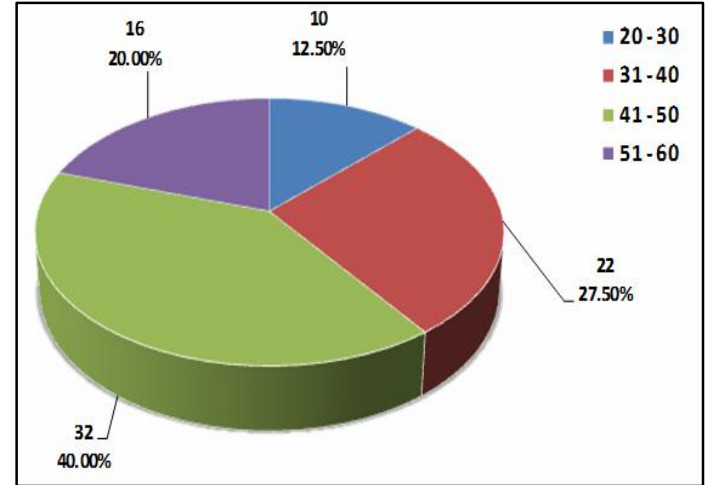

Figure (1) Age distribution of all studied cases

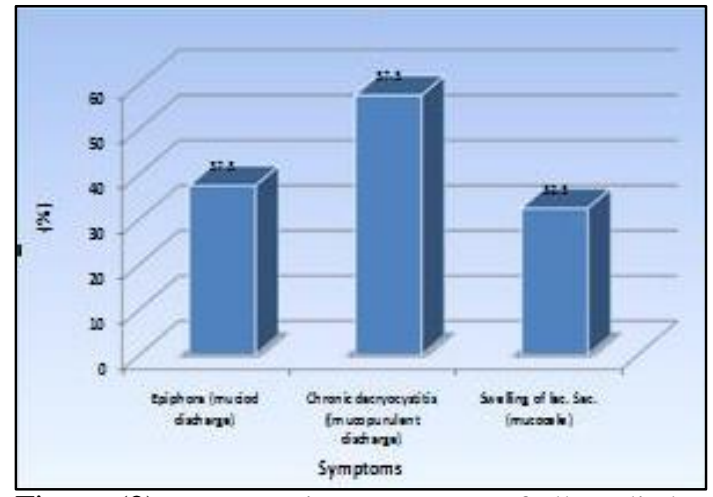

Figure (2) Pre operative symptoms of all studied cases

Table (1) Comparison between external and endonasal DCR regarding success rate.

\begin{tabular}{|c|c|c|c|c|c|c|}
\hline \multirow{2}{*}{ Variable } & \multicolumn{2}{|c|}{$\begin{array}{c}\text { Group (I) } \\
\text { EX. DCR }(n=40)\end{array}$} & \multicolumn{2}{|c|}{$\begin{array}{c}\text { Group (II) } \\
\text { END. DCR }(n=40)\end{array}$} & \multirow{2}{*}{$X^{2}$} & \multirow{2}{*}{ P. V (Sig.) } \\
\hline & No. & $\%$ & No. & $\%$ & & \\
\hline Success rate & 33 & 82.5 & 31 & 77.5 & 0.31 & $0.58^{\mathrm{NS}}$ \\
\hline
\end{tabular}

NSNot Significant.

Table (2) Comparison between subgroups of external and endonasal DCR regarding success rate.

\begin{tabular}{|c|c|c|c|c|c|}
\hline \multirow[b]{2}{*}{ Variable } & \multicolumn{2}{|c|}{$\begin{array}{c}\text { Group (I) EX. DCR } \\
(n=40)\end{array}$} & \multicolumn{2}{|c|}{$\begin{array}{c}\text { Group (II) END. DCR } \\
(\mathrm{n}=\mathbf{4 0})\end{array}$} & \multirow{2}{*}{$\begin{array}{l}\text { P. V } \\
\text { (Sig.) }\end{array}$} \\
\hline & $\begin{array}{c}\text { I a }(\mathrm{n}=20) \\
\text { No. }(\%)\end{array}$ & $\begin{array}{c}\mathrm{I} b(\mathrm{~b}=20) \\
\text { No. }(\%)\end{array}$ & $\begin{array}{c}\text { II a }(n=20) \\
\text { No. }(\%)\end{array}$ & $\begin{array}{c}\text { II b }(\mathrm{n}=20) \\
\text { No. }(\%)\end{array}$ & \\
\hline Success rate & $17(85.0 \%)$ & $16(80.0 \%)$ & $16(80.0 \%)$ & $15(75.0 \%)$ & $0.89^{\mathrm{NS}}$ \\
\hline P. V (Sig.) & \multicolumn{2}{|c|}{$0.67^{\mathrm{NS}}$} & \multicolumn{2}{|c|}{$0.71^{\mathrm{NS}}$} & --- \\
\hline
\end{tabular}

NSNot Significant.

Table (3) Comparisons among groups regarding operative time.

\begin{tabular}{|c|c|c|c|c|c|}
\hline \multirow[b]{2}{*}{ Variable } & \multicolumn{2}{|c|}{$\begin{array}{c}\text { Group (I) EX. DCR } \\
(n=40)\end{array}$} & \multicolumn{2}{|c|}{$\begin{array}{c}\text { Group (II) END. DCR } \\
(\mathrm{n}=\mathbf{4 0 )}\end{array}$} & \multirow{2}{*}{$\begin{array}{l}\text { P. V } \\
\text { (Sig.) }\end{array}$} \\
\hline & $\begin{array}{c}\mathrm{I} \text { a } \\
(\mathrm{n}=20) \\
\text { Mean } \pm \text { SD }\end{array}$ & $\begin{array}{c}\mathrm{I} b \\
(\mathrm{n}=20) \\
\text { Mean } \pm \text { SD }\end{array}$ & $\begin{array}{c}\text { II a } \\
(\mathrm{n}=20) \\
\text { Mean } \pm \text { SD }\end{array}$ & $\begin{array}{c}\text { II b } \\
(\mathrm{n}=20) \\
\text { Mean } \pm \text { SD }\end{array}$ & \\
\hline $\begin{array}{l}\text { Operative } \\
\text { time (min.) }\end{array}$ & $61.8^{a} \pm 6.4$ & $53.2^{b} \pm 7.9$ & $49.1^{b} \pm 5.2$ & $41.2^{c} \pm 7.7$ & $<0.01 * *$ \\
\hline
\end{tabular}

** Significant $(p<0.01)$

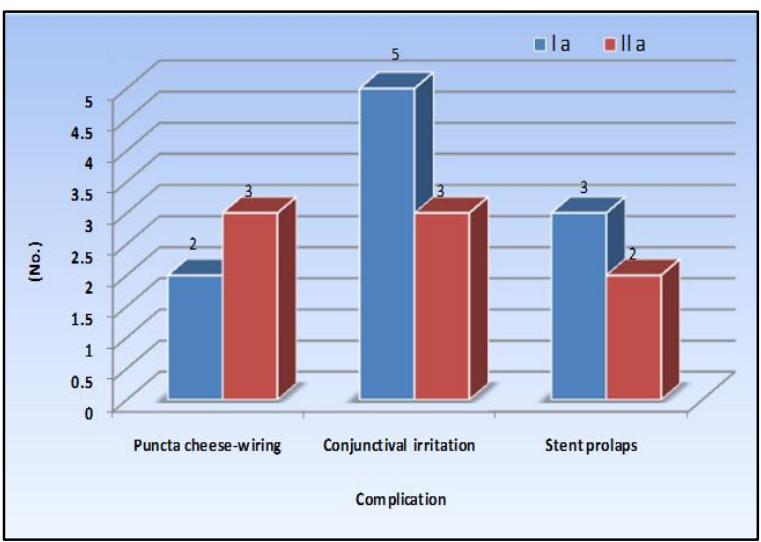

Figure (3) Complication regarding intubation 


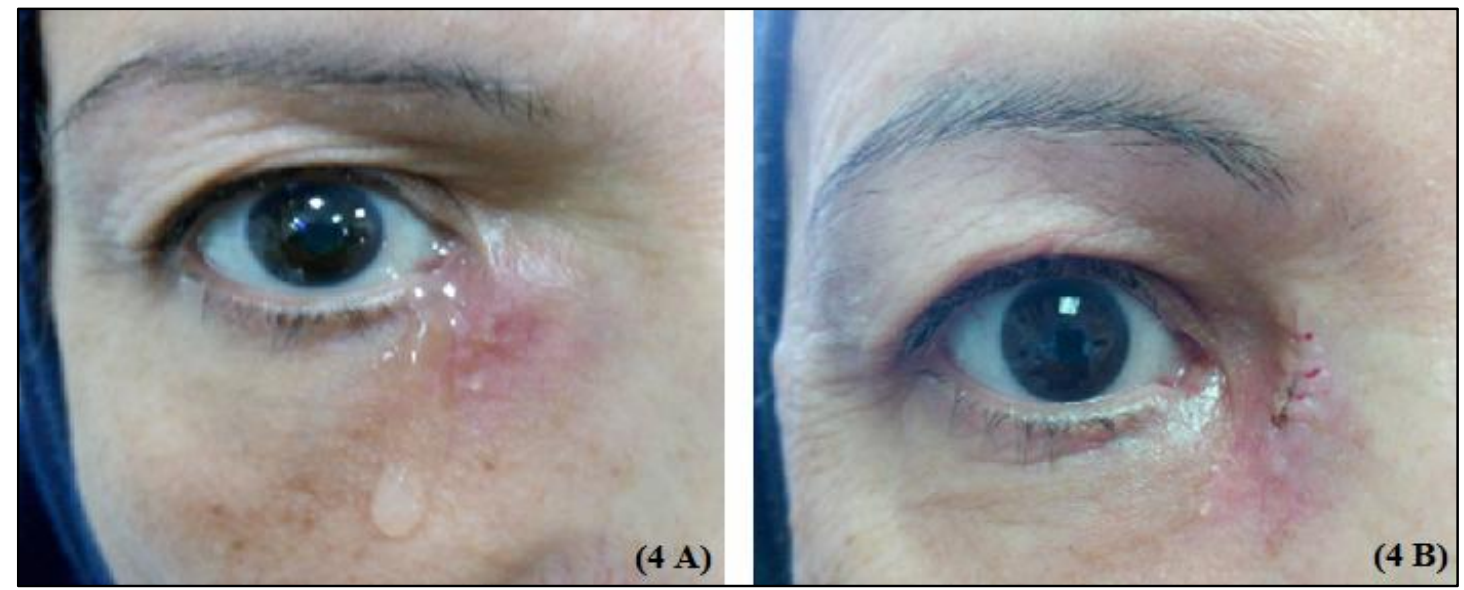

Figure (4) $\underline{\mathbf{a}}$ Shows a case of mucoid lacrimal discharge (preoperative), $\underline{\mathbf{b}}$. 1 week post operative after successful EX. DCR. without intubation

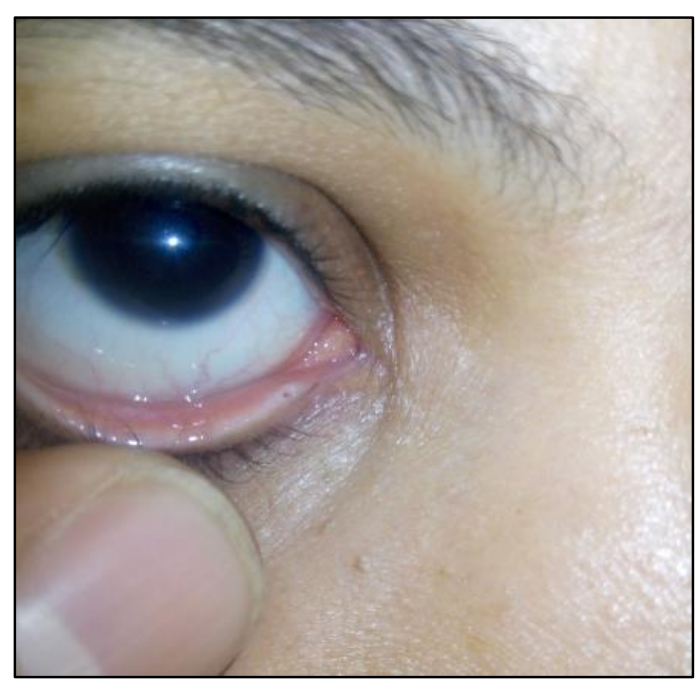

Figure (5) A case of successful endonasal DCR without intubation 3 months post operative.

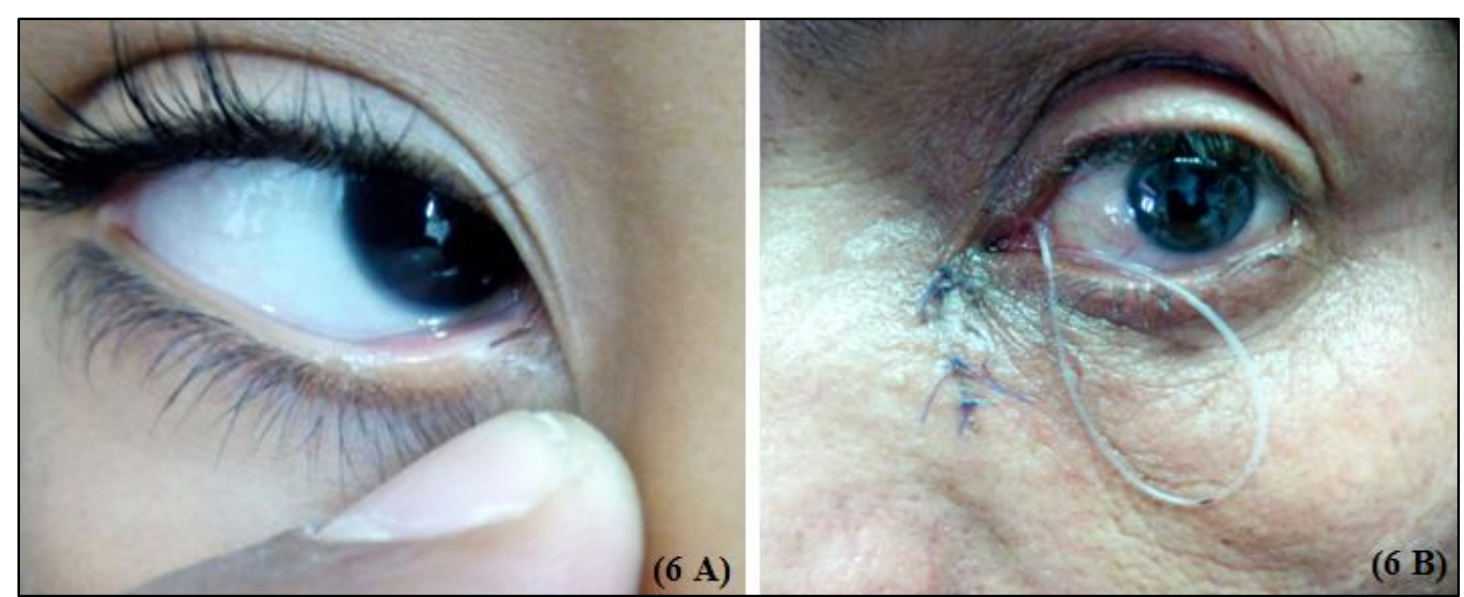

Figure (6) Complications regarding intubation, a. shows case of punctal cheese-wiring, $\underline{\mathbf{b}}$. case of stent prolapse.

\section{Discussion}

In our study the age of patients ranged between 22 and 58 year with age predominance was between (31-50) which were 22 cases $(27.5 \%)$ and in group (41-50) which were 32 cases (40\%) with mean age of 44 years. Similarly, Ambili and Rajini studied the success rate comparison of external dacryocystorhi- 
nostomy with and without silicone intubation and they found that primary acquired NLDO was to be more common in 30-40 years of age [6]. Talpur et al., reported that the mean age of their patients was 34 years [7]. Also, our results are comparable with those of Ali \& Ahmad who reported that $70.8 \%$ of their patients were between 31 and 50 years of age [8]. While Solermachin et al, reported the mean age of 65 years [9]. Females were predominant in our study than males with male to female ratio of 23 / $51(31.1 / 68.9 \%)$. Increased predilection in women has been mentioned in literature, the theories proposed include smaller dimension of middle and lower nasolacrimal duct, changes in anteroposterior dimensions of bony nasolacrimal duct with osteoporotic changes. Similar female preponderance was also reported by Ali and Ahmad (98.6\%) [8], (74\%) by Talpur et al. [7] (71\%) by Akhund in 2004, [10] (76\%) by Ucgun et al, [11] and (73.91\%) by Solermachin et al. [9]. In our study, the overall success rate in external DCR was $82.5 \%$ (33 cases from 40 ), however, the overall success rate in endonasal DCR was $77.5 \%$ (31 cases from 40) with no significant difference between external and endoscopic DCR. Our results are in agreement of Dolman who reported complete success in $90.2 \%$ of patients with EX-DCR and in $89.1 \%$ in patients with EN-DCR. (1) In prospective study, Zaidi showed a $100 \%$ success rate for EXT-DCR and an $86 \%$ success rate for ENS. DCR. It has been reported that success was based on the degree of epiphora after 6 months and assessment of patency through syringing [12]. Furthermore, many studies suggest comparable results for both procedures and reported that the two different techniques are acceptable alternatives and the success rate of both the procedure is comparable as that reported by Karim et al, reported success rate $93.2 \%$ for EN-DCR and 91\% for EX-DCR, [13] Saroj and Rashmi, reported success rate $90 \%$ for EN-DCR and $95 \%$ for EX-DCR, [14] Leong et al, reported success rate $86 \%$ for EN-DCR and $94 \%$ for EX-DCR, [15] Sharma reported success rate $88.5 \%$ for $\mathrm{EN}$ DCR and $90.5 \%$ for EX-DCR [16] and Ben Simon et al, reported success rate $84 \%$ for EN-DCR and $90 \%$ for EXDCR [17]. In the present study, no significant differences in success rate were found between external DCR with intubation (group Ia) and external DCR without intubation (group Ib) and also in the same line, no significant differences were observed between endonasal DCR with intubation (group IIa) and endonasal DCR without intubation (group IIb). Our results are in agreement of Ambili and Rajini who found that the success rate at 6 months after surgery was 95\% for DCR with intubation and $90 \%$ for DCR without intubation, they concluded that External DCR without intubation yielded equally good results as External DCR with intubation [6]. Similarly, Saiju et al, studied a Prospective randomised comparison of external dacryocystorhinostomy with and without silicone intubation in 100 patients and used silicone tube in 44 patients and not used in 56 patients. They found that, after six month follow up, the success rates were $90 \%$ in silicone group, and $87 \%$ in silicone free group, and the difference between the groups was insignificant. They also reported that silicone tube increased the cost of the surgery as $20 \%$ [18]. Additionally, in a study conducted by Zaman et al, in 2005 the success rates at one year after surgery was $97.5 \%$ for DCR with intubation and $95 \%$ for DCR without intubation and there was no statistically significant difference between 
the two groups [19]. Similarly, Walland and Rose found no statistically significant difference in their failure rates between intubated and non intubated cases. These results are in comparable to our findings [20]. In a prospective randomized trial with a 12-month follow-up of bicanalicular silicone intubation in endonasal endoscopic mechanical dacryocystorhinostomy for PANDO, Chong et al, reported that there was no statistical difference in the success rates between patients with $(96.3 \%)$ and without (95.3\%) intubation., also, there was no difference in the incidence or the time taken to develop granulation tissue between the two groups of intubation and non intubation [21]. In addition, Feng et al, in a meta-analysis that included five randomized controlled trials and four cohort studies, reported that there was no benefit from silicone tube intubation in primary DCR cases [22]. Similarly, in a single comparative study, Unlu et al., studied the comparison of surgical outcomes in primary endoscopic dacryocystorhinostomy with and without silicone intubation and they found $91.7 \%$ anatomical success in intubated cases compared to $92.3 \%$ in their non intubated subgroup and there is no significant difference between intubated and non intubated cases regarding the success rate. These results are in comparable to our findings [23]. On contrary, Smirnov et al. studied intubation versus non intubation DCR in randomized controlled study, In their study, they presented 46 patient with primary endoscopic DCR with absence of canalicular pathology and performed by three rhinologists, Thay reported a $100 \%$ anatomical and functional success in the non intubated group, in comparison to $78 \%$ in the intubated subgroup, a difference that was statistically significant [4]. Furthermore, Panday and colleagues studied factors that influence outcome of external dacryocystorhinostomy, they presented a retrospective review of 338 DCR cases found that intubation time of longer than 6 months was associated with better outcome compared with shorter intubation times $(\mathrm{P}=$ 0.002) [24]. In a study conducted by Shagufta and Tejit, they found the success rate for external DCR without silicone intubation was $80 \%$ while the success rate for DCR with silicone intubation was to $92 \%$. They reported that the use the silicone tube prevent closure of common canalicular opening which is the commonest cause of failure thereby enhancing the success rate of DCR [25]. In earlier study, Allen and Berlin compared patients without canalicular disease who underwent primary DCR in which the silicone intubation was the only variable factor. They found a failure of $14.5 \%$ in the intubated group and $5.0 \%$ in the non-intubated group, the failures did not appear to be related to canalicular damage. They went as far as to state that intubation was associated with a statistically significant increase in the failure rate of primary DCR and the routine use of silicone tubing in DCR should be avoided unless a specific canalicular obstruction was present [26]. Other studies advocates a selective indication for use of silicon stent in DCR as in recurrent DCR surgery, excessive intraoperative hemorrhage, small or altered sac anatomy, narrow nasal cavities and poor mucosal flap formation [20, 27-29]. In our study, the higher operative time mean was recorded in group Ia (61.8 min.), follow it with a significant difference group Ib (53.2 min.), however the lower mean operative time was recorded in group IIb (41.2 min.). Overall, DCRs without intubation recorded significantly lower mean operative time compared to with intubation DCRs. Our results are in agreement of Gül et al, who studied 
the effect of silicone tube intubation in external dacryocystorhinostomy. In their study, they reported that there was no significant difference in the success between DCR with silicone intubation which was (89.2\%) and silicone free
DCR which was $(88.1 \%)$. The cost of the silicone rod was one fourth of the total cost of the DCR surgery and finally they reported that the intubation increases the surgical time and also the duration of general anesthesia [30].

\section{Conclusions}

On the basis of our observations, the results of external and endonasal dacryocystorhinostomy are comparable, so, we could conclude that the two different studied techniques are acceptable alternatives for treatment of nasolacrimal duct obstruction with a comparable success rate. Also, the results of endoscopic and external dacryocystorhinostomy with silicone intubation were comparable to these result without intubation after a follow-up period of 6 months, the difference in the results is statistically insignificant. Hence, we could report that using of silicone tube has no significant beneficial effect in the surgical success of primary dacryocystorhinostomy and there is no need for its routine use. The use of silicone tube in primary dacryocystorhinostomy increases both the cost and the time of the surgery. Furthermore, there are some possible complications that may happened from the tube as corneal erosion or ulcer, punctal or canalicular cheesewiring, pyogenic granuloma formation, canalicular infection, stent prolaps, nasal irritation, nasal bleeding and tube displacements. One of our study limitations is the small sample size. So, further studies with larger sample size are warranted.

\section{References}

1. Dolman, P. Comparison of external dacryocystorhinostomy with nonlaserendonasal dacryocystorhinostomy. Ophthalmology 2003; 110: 78-84.

2. Buttanri, I., Serin, D. Silicone Intubation indications in external dacryocystorhinostomy. Med Hypothesis Discov Innov Ophthalmol. 2014; 3 (4): 101-102.

3. Madge, S., Selva, D. Intubation in routine dacryocystorhinostomy: Why we do what we do. Clin Experiment Ophthalmol. 2009; 37: 620-623.

4. Smirnov, G., Tuomilehto, H., Teräsvirta, M., Tuomilehto H., Terasvirta, M., Nuutinen, J., Seppa, J. Silicone tubing is not necessary after primary endoscopic dacryocysto-rhinostomy: A prospective randomized study. Am J Rhinol. 2008; 22: 214-217.

5. Monka, A., Zhungli, S. Silicone intubation in external dacryocystorhinostomy. International Journal of Science and Research. 2015; 4 (12): 74-81

6. Ambili, K., Rajini, K. Success rate comparison of external dacryocystorhinostomy with and without silicone intubation for the treatment of primary nasolacrimal duct obstruction. Journal of Evidence based Medicine and Healthcare. 2015; 2: 4508-4517.

7. Talpur, K., Jatoi, S., Khan, S. Dacryocystorhinostomy: A clinical report of 54 cases. Pak J Ophthalmol. 1998; 14: 169-171.

8. Ali, A., Ahmad, T. Dacryocystorhinostomy a review of 51 cases. Pak $\boldsymbol{J}$ Ophthalmol. 2001; 17: 122-128.

9. Solermachin, J., Castillo, J. De Gregorio, M., Medrano, J., Lacrimal duct obstruction treated with lacrimonasal stent. Arch Soc Esp Oftalmol 2003; 78: 315318.

10. Akhund, A. A comparative study between intubated and non-intubated DCR's in NLD obstruction. Pak $\boldsymbol{J}$ Ophthalmol. 2004; 20: 61-64.

11. Ucgun, N., Hobal, B., Gursel, E. Dacryocystorhinostomy: Surgical results and the factors affecting success. TKlinOftalmolji. 2000; 9: 225-229.

12. Zaidi, F., Symanski, S., Olvera, J. Clinical trial of endoscopic vs external dacryocystorhinostomy for partial nasolacrimal duct obstruction. Eye 2011; 25: 1219-1224.

13. Karim, R., Ghabrial, R., Lynch, T., Tang, B. A comparison of external 
and endoscopic endonasal dacryocystorhinostomy for acquired nasolacrimal duct obstruction. ClinOphthalmol. 2011; 5: 979-989.

14. Saroj, G., Rashmi, G. Conventional dacryocystorhinostomy versus endonasal dacryocystorhinostomy a comparative study. Indian J Otolaryngol Head Neck Surg. 2010; 62: 296-298.

15. Leong, S., Macewen, C., White, P. A systematic review of outcomes after dacryocystorhinostomy in adults. $\mathbf{A m}$ J Rhinol Allergy. 2010; 24: 81-90.

16. Sharma, B. Non-endoscopic endonasal dacryocystorhinostomy versus external dacryocystorhinostomy. Kathmandu Univ Med J. 2008; 6: 437-442.

17. Ben Simon, G., Joseph, J., Lee, S. External versus endoscopic dacryocystorhinostomy for acquired nasolacrimal duct obstruction in a tertiary referral center. Ophthalmology. 2005; 112: 1463-1468.

18. Saiju, R., Morse, L., Weinberg, D., Shrestha, M., Ruit, S. Prospective randomised comparison of external dacryocystorhinostomy with and without silicone intubation. $\boldsymbol{B r} \boldsymbol{J}$ Ophthalmol. 2009; 93 (9): 1220-1222.

19. Zaman, M., Babar, T., Abdullah, A. Prospective randomized comparison of dacryocystorhinostomy (DCR) with and without intubation. Pak $\boldsymbol{J}$ Med. Res., 2005; 44 (2): 75-78.

20. Walland, M., Rose, G. Factors affecting the success rate of open lacrimal surgery. Br J Ophthalmol. 1994; 78: 888-891.

21. Chong K., Lai F., Ho M., Luk A., Wong B., Young, A. A randomized trial on silicone intubation in endoscopic mechanical dacryocystorhinostomy (SEND) for primary nasolacrimal duct obstruction. (Report). Ophthalmology. 2013; 120: 2139-2145.
22. Feng, Y., Cai, J., Zhang, J., Han, X. A meta-analysis of primary dacryocystorhinostomy with and without silicone intubation. Can J Ophthalmol. 2011; 46: 521-527.

23. Unlu, H., Aslan, A., Toprak, B., Guler, C. Comparison of surgical outcomes in primary endoscopic dacryocystorhinostomy with and without silicone intubation. AnnOtolRhinolLaryngol. 2002; 111: 704-709.

24. Pandy, V., Lee, S., Benger, R., Danks, J., Kourt, G., Martin, P. External dacryocystorrhinostomy: Assessing factors that influence outcome. Orbit. 2010; 29: 291-297.

25. Shagufta, R., Tejit, S. External dacryocystorhinostomy with \& without silicon tube intubation in chronic dacryocystitis with nasolacrimal duct block. JK Science. 2013; 15: 24-27

26. Allen, K., Berlin, A. Dacryocystorhinostomy failure: Association with nasolacrimal silicone intubation. Ophthalmic Surg. 1989; 20: 486-489.

27. Rosser, $P$. There is no use crying over spilt tears: the surgical management of primary acquired nasolacrimal duct obstruction. Aust N Z J Ophthalmol. 1999; 27: 95-100.

28. Choung, H., Khwarg, S. Selective non-intubation of a silicone tube in external dacryocystorhinostomy. Acta Ophthalmol Scand. 2007; 85: 329-332.

29. Callejas, C., Tewfik, M., Wormald, P. Powered endoscopic dacryocystorhinostomy with selective stenting. Laryngoscope. 2010; 120: 1449-1452.

30. Gül, A., Duran, M., Can, E. The effect of silicone tube intubation in external dacryocystorhinostomy. Acta Med Anatol. 2015; 3 (1): 1-4 